\title{
Avaliação do desempenho de semeadoras manuais
}

José P. Molin ${ }^{1}$, Leonardo A. A. Menegatti² \& Leandro M. Gimenez ${ }^{3}$

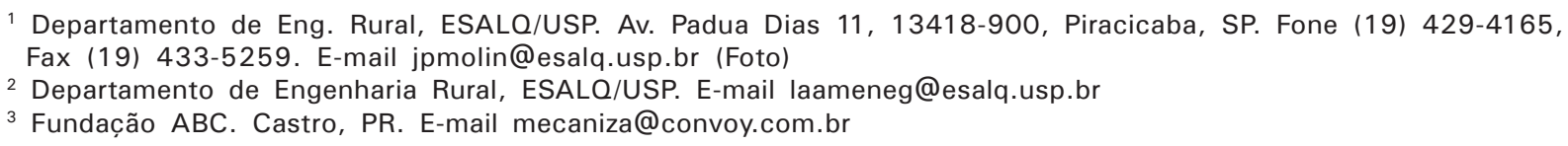

Protocolo $155-21 / 12 / 2000$

\begin{abstract}
Resumo: Um grande número de pequenas propriedades rurais no Brasil utiliza semeadoras manuais para a operação de semeadura. O fator limitante para a utilização de tratores e equipamentos de maior rendimento nessas condições são terrenos pedregosos ou declivosos e disponibilidade de capital. As semeadoras manuais existentes no mercado mantêm o mesmo princípio desde o início de sua utilização e não sofreram grandes melhorias. Neste trabalho avaliaram-se semeadoras existentes no mercado, classificando-as quanto à regularidade de vazão dos seus mecanismos dosadores. Para a avaliação estabeleceu-se, como meta, a vazão de duas sementes por ciclo. Algumas semeadoras resultaram em baixo desvio-padrão e média próximo de duas sementes por ciclo, enquanto outras apresentaram desempenho deficiente. Não houve algum tipo de mecanismo dosador que se destacasse, sendo seus efeitos encobertos pela qualidade construtiva das máquinas.
\end{abstract}

Palavras-chave: semeadora manual, agricultura familiar, semeadura em covas

\section{Evaluation of manual planters}

\begin{abstract}
In Brazil, a great number of small farms still use manual planters, especially in hilly and stony areas. These machines have not received significant design improvements since the start of their usage. Some of these planters available in the market have been tested for their seeding performance for corn. Each machine was set up to deliver two seeds each time. Only a few planters resulted in a low standard deviation and number of seeds close to the target. The performance of the seed meter was affected by the manufacturing quality of the machines.
\end{abstract}

Key words: manual planter, small farm, punch planter

\section{INTRODUÇÃO}

A produção de alimentos é realizada por apenas $30 \%$ da população mundial, enquanto os outros $70 \%$ vivem em áreas urbanas, não produzindo o que consomem e a tendência dessa disparidade continua crescendo. Grande parte deste contingente produz alimentos somente para subsistência utilizando, para isto, uma série de ferramentas e máquinas bastante simples. As semeadoras manuais são máquinas muito úteis e versáteis e vêm sendo utilizadas há muito tempo em pequenas propriedades rurais, além de serem transmitidas de geração a geração, mantendo suas características estruturais e de funcionamento. A sobrevivência desse sistema produtivo no Brasil, tanto das unidades criadas ainda na fase de imigração como daquelas mais recentes, produto dos programas de reforma agrária, merece maior atenção por parte dos setores responsáveis por programas de fomento e política agrária.
Monegat (1996) destaca que o agricultor que utiliza tração animal para as operações de preparo do solo e capina e faz a semeadura com uma máquina manual, percorre de 80 a $150 \mathrm{~km} \mathrm{ha}^{-1}$ de lavoura de milho em uma safra. Enfatiza, ainda, que, após 40 anos de trabalho cultivando $10 \mathrm{ha} \mathrm{ano}^{-1}$ de milho, esse agricultor já terá dado uma volta ao redor do globo, a pé.

Mialhe et al. (1985) conduziram um trabalho de diagnóstico em diferentes regiões brasileiras, dirigido à viabilização da motomecanização em propriedades agrícolas com este perfil e evidenciaram que são várias as regiões geográficas brasileiras que apresentam características de concentração de pequenas propriedades agrícolas familiares, associadas a solos declivosos e, normalmente, com alta pedregosidade.

A mecanização da operação de preparo do solo desse tipo de propriedade agrícola tem sido estudada em diferentes regiões e enfoques (Molin \& Ogliari, 1990; Casão Júnior et al., 1988). A semeadura, por ser uma operação de menor demanda de potência, consagrou-se pelo método totalmente manual, 
com a utilização de máquinas regionalmente conhecidas como "saraquá" ou "matraca". Algumas tentativas de adaptação e otimização têm sido propostas (Lal \& Nunes, 1981; Casão Júnior et al., 1986; Casão Júnior \& Yamaoka, 1990) porém sempre embasadas em máquinas de tração animal, solução esta perfeitamente viável em áreas em que a declividade e a pedregosidade não são os maiores limitantes, caso em que a adoção de semeadoras de uma ou duas linhas para tração animal, semelhantes àquelas de tração mecânica, é tecnicamente recomendada, mas para as áreas de encostas pedregosas nenhuma solução alternativa tem sido oferecida e os agricultores ainda utilizam a mesma semeadora manual que seus ancestrais trouxeram da Europa há mais de um século. Sendo elas transportadas manualmente, o operador escolhe o local onde vai colocar a semente, desviando a semeadora de pedras e outros impedimentos. Sua capacidade operacional é baixa, variando conforme a cultura e o operador. São máquinas que se adaptam também ao sistema de semeadura direta, além de alguns modelos realizarem as operações de semeadura e adubação.

A despeito de sua importância social e econômica, a semeadora manual sofreu poucas melhorias ao longo dos anos e poucos dados são disponíveis a respeito de suas características de desempenho. Em função disso, o presente trabalho foi desenvolvido com o objetivo de descrever e classificar os principais modelos de semeadoras e semeadoras-adubadoras manuais, propor uma metodologia para avaliar seu desempenho e sugerir melhorias nas máquinas de mercado.

\section{MATERIAL E MÉTODOS}

Inicialmente, foram resgatadas quinze semeadoras e semeadoras-adubadoras manuais, de diferentes fabricantes e

(A)
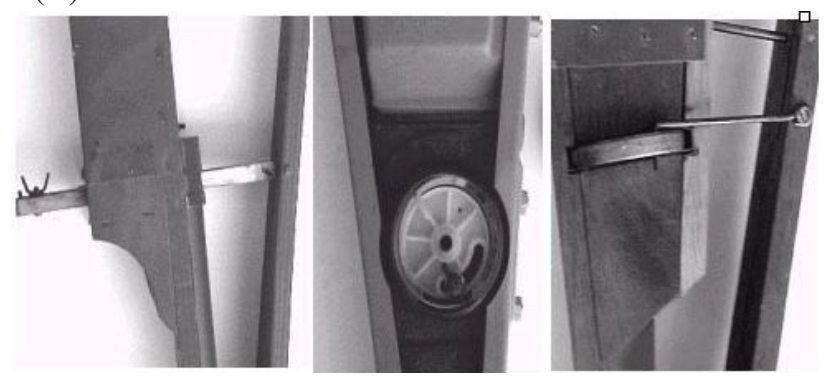

(C)

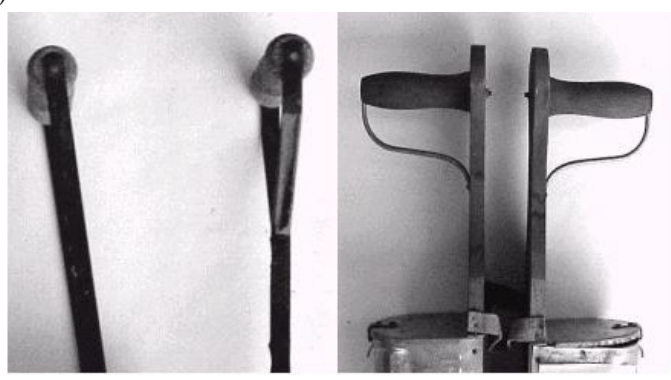

diversas regiões do centro-sul do Brasil, visando-se obter a maior diversidade possível em máquinas. Para a descrição e análise construtiva dessas máquinas elaborou-se uma ficha descritiva com informações julgadas relevantes para a caracterização das semeadoras, como capacidade dos reservatórios de semente e adubo, quando este existia, características estruturais do chassi, empunhadura, mecanismo dosador de adubo e de semente e tubo condutor, número e tipo de ponteira e do peso do conjunto.

Os mecanismos dosadores foram classificados como de lingüeta ou cilíndricos, ambos de movimento alternativo, retilíneo e circular, respectivamente (Figura 1A) com posição horizontal ou vertical. Dosadores tipo lingüeta podem ter regulagens em extensão da abertura de um furo oblongo ou número de furos na lingüeta, enquanto os cilíndricos permitem variar o número de furos para os horizontais ou o grau de abertura para os verticais. As ponteiras foram classificadas como simples ou compostas (Figura 1B); ponteiras simples são aquelas que depositam semente ou adubo a uma profundidade e a ponteira composta deposita semente e adubo em profundidades diferentes. Foram obtidas, também, semeadoras com duas ponteiras simples separadas. As empunhaduras foram classificadas como de posição longitudinal ou transversal ao eixo da articulação da semeadora (Figura 1C). Observaram-se máquinas com um ou dois reservatórios plásticos ou metálicos, posicionados interna, externamente ou centrados no braço (Figura 1D).

Um ensaio para avaliação do fluxo de massa das semeadoras foi realizado, utilizando-se um mecanismo de biela e manivela acionado por um motor de $30 \mathrm{~W}$ e $12 \mathrm{~V}$, corrente contínua, com 1 $\mathrm{Hz}$, simulando a operação em ritmo de campo. As máquinas foram carregadas até a metade do volume do reservatório e ensaiadas em três regulagens (máxima, média e mínima) coletando-se a quantidade de sementes dosadas. $\mathrm{O}$ ensaio foi conduzido com

(B)
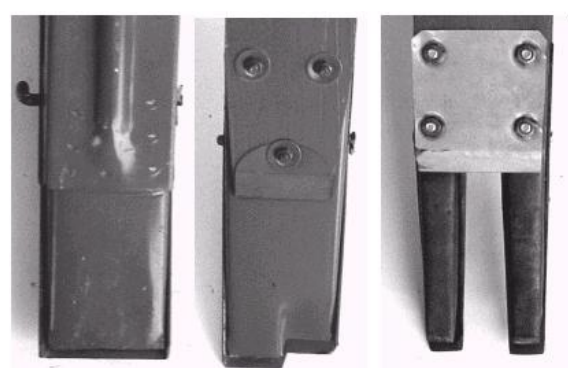

(D)

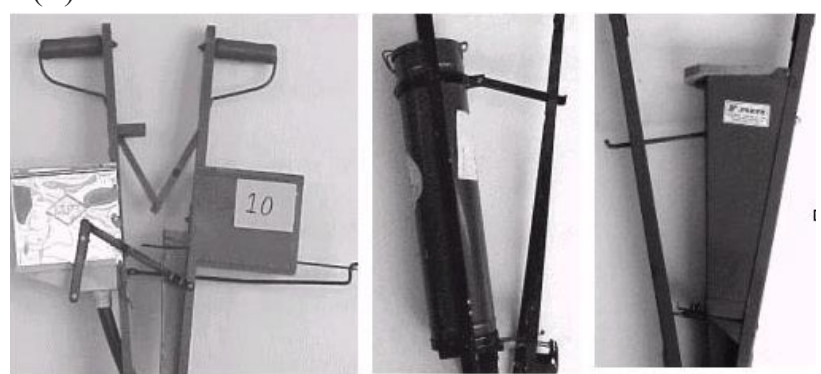

Figura 1. Tipos de mecanismo dosador: (A) lingüeta na posição horizontal (esquerda), cilíndrico vertical (centro) e cilíndrico horizontal (direita); (B) tipos de ponteiras: simples (esquerda), composta (centro) e simples dupla (direita); (C) tipos de empunhadura: longitudinal (esquerda) e transversal (direita); (D) tipos de reservatório: dois externos (esquerda), único central (centro) e único interno (direita) 
três repetições de sessenta ciclos e o número de sementes convertido para sementes por ciclo. Em todos os ensaios foram utilizadas sementes de milho, por ser a cultura mais utilizada com esse tipo de máquina.

Para o ensaio de dosagens individuais de semente, o mesmo mecanismo descrito anteriormente foi utilizado, porém colocado sobre uma bancada de ensaio de semeadoras, com uma esteira rolante simulando a operação de campo em ritmo contínuo de 1 ciclo s$^{-1}$ (Figura 2). O objetivo do ensaio foi caracterizar a regularidade de vazão do mecanismo dosador de cada semeadora. O experimento teve como meta a obtenção de 40000 sementes ha $^{-1}$, com um espaçamento entre linhas de $1 \mathrm{~m}$ e o espaço entre covas considerado de $0,5 \mathrm{~m}$, resultando em 2 sementes por cova. Em situações reais, o espaçamento depende de cada operador, visto que o comprimento do passo do operador é que o determina. Utilizou-se uma esteira com $15 \mathrm{~m}$ de comprimento, movendo-se numa velocidade que possibilitou 50 golpes da máquina por repetição, com três repetições por máquina.

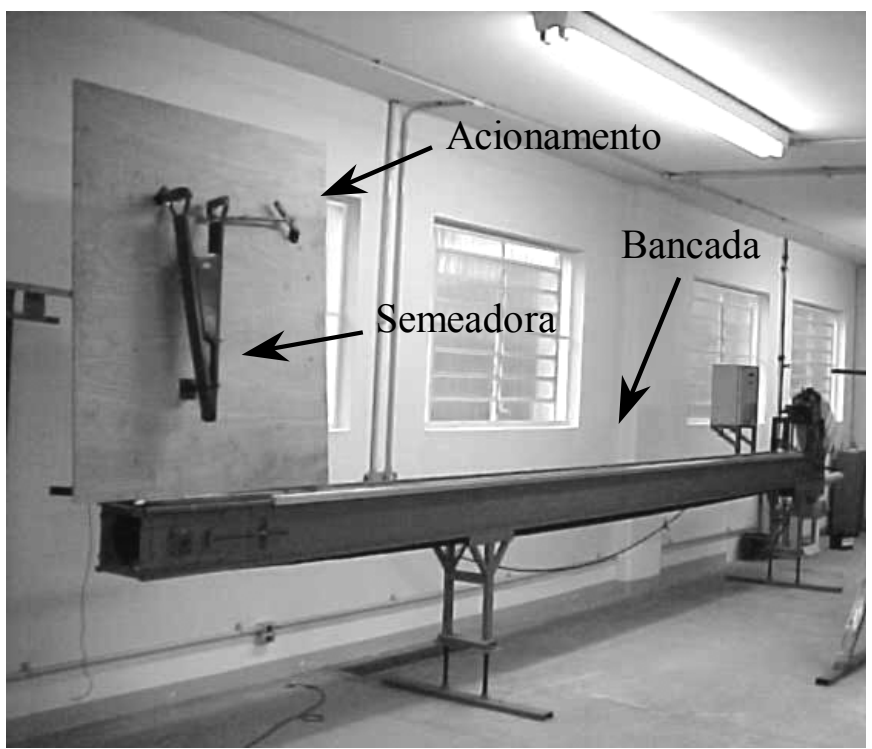

Figura 2. Semeadora montada na bancada, para ensaio de dosagens individuais de sementes

\section{RESULTADOS E DISCUSSÃO}

A elaboração das fichas com características estruturais das semeadoras permitiu estabelecer-se padrões de classificação das máquinas, com base nos seus componentes. Foram documentadas máquinas de cinco fabricantes e o resumo das características construtivas é apresentado na Tabela 1. Os resultados do ensaio de vazão são apresentados na Tabela $2 \mathrm{e}$ evidenciam a grande irregularidade na vazão do mecanismo dosador das diferentes máquinas e na regulagem dentro de cada máquina. Em algumas não havia regulagem na posição de vazão preestabelecida, apenas máxima e mínima ou, então, pontos fixos de regulagem em número par, que não permitiam uma regulagem para a posição média.

Nas máquinas 6 e 13 houve pouca resposta na vazão de sementes com a mudança da regulagem da posição de média para a de máxima, enquanto na regulagem mínima não se obteve fluxo de sementes durante o ensaio. Essas semeadoras obtiveram 1,28 e 0,58 sementes por ciclo na posição de regulagem máxima, indicando não serem adaptadas à semeadura de duas sementes por ciclo. Vazões na regulagem mínima foram apresentadas apenas pelas semeadoras 1 e 10, destacando-se ainda por terem boa resposta da dosagem de sementes a variações da regulagem, sendo ambas de mecanismo dosador tipo lingüeta. Nessas máquinas, pequenas variações na regulagem dos mecanismos dosadores afetam pouco a vazão de sementes e permitem melhor regulagem no espectro de 1,00 a 2,50 sementes por ciclo. A semeadora 8 também apresentou boa resposta à regulagem do mecanismo dosador, porém apenas entre as posições média e máxima, nas quais atingiu 2,89 sementes por ciclo. As semeadoras 2, 3, 5, 7 e 15 se enquadraram numa faixa intermediária de variação de vazão, atingindo até 4,98 sementes por ciclo na regulagem de abertura máxima, porém sem fluxo de sementes na posição de regulagem mínima. As semeadoras 4, 9,11,12 e 14 apresentaram alta variação de vazão entre a regulagem média e máxima, não havendo vazão na regulagem mínima, indicando que pequenas variações na regulagem do mecanismo dosador acarretam grandes variações na vazão. Um mecanismo dosador pouco sensível a pequenas alterações é recomendável nessas máquinas, a exemplo dos mecanismos apresentados pelas semeadoras $1 \mathrm{e}$

Tabela 1. Resumo das características construtivas das máquinas analisadas e ensaiadas

\begin{tabular}{|c|c|c|c|c|c|c|c|c|c|c|c|}
\hline \multirow{2}{*}{\multicolumn{2}{|c|}{ Máquina }} & \multirow{2}{*}{\multicolumn{2}{|c|}{ Reservatório }} & \multirow{3}{*}{$\begin{array}{c}\text { Posição } \\
\text { Empunhadura }\end{array}$} & \multirow{2}{*}{\multicolumn{2}{|c|}{ Ponteiras }} & \multicolumn{4}{|c|}{ Dosadores } & \multirow{3}{*}{$\begin{array}{c}\text { Peso } \\
(\mathrm{g})\end{array}$} \\
\hline & & & & & & & \multicolumn{2}{|c|}{ Semente } & \multicolumn{2}{|c|}{ Adubo } & \\
\hline Núm. & Fabricante & Num. & Posição & & Tipo & Num. & Tipo & Posição & Tipo & Posição & \\
\hline 1 & Fitarelli & 1 & externo & transversal & Simples & 1 & Lingüeta & Horizontal & & & 2670 \\
\hline 2 & Fitarelli & 2 & externo & transversal & Simples & 2 & Lingüeta & Horizontal & Cilíndrico & Vertical & 3480 \\
\hline 3 & Krupp & 1 & central & longitudinal & Simples & 1 & Lingüeta & Horizontal & & & 2266 \\
\hline 4 & Krupp & 1 & externo & transversal & Simples & 1 & Lingüeta & Horizontal & & & 2350 \\
\hline 5 & Krupp & 1 & interno & longitudinal & Simples & 1 & Cilíndrico & Horizontal & & & 2780 \\
\hline 6 & Krupp & 2 & central & longitudinal & Composta & 1 & Lingüeta & Horizontal & Cilíndrico & Vertical & 3150 \\
\hline 7 & Guimatra & 2 & interno & longitudinal & Simples & 1 & Cilíndrico & Vertical & Cilíndrico & Vertical & 3750 \\
\hline 8 & Forte Máq. Agr. & 1 & interno & longitudinal & Simples & 1 & Lingüeta & Horizontal & & & 2800 \\
\hline 9 & Krupp & 1 & central & longitudinal & Simples & 1 & Cilindro & Vertical & & & 2320 \\
\hline 10 & Krupp & 2 & externo & transversal & Composta & 1 & Lingüeta & Horizontal & Cilíndrico & Vertical & 3590 \\
\hline 11 & Mebuki & 1 & interno & longitudinal & Simples & 1 & Cilíndrico & Vertical & & & 3500 \\
\hline 12 & Krupp & 2 & externo & transversal & Composta & 1 & Lingüeta & Horizontal & Cilíndrico & Vertical & 3340 \\
\hline 13 & Guimatra & 1 & interno & longitudinal & Simples & 1 & Lingüeta & Horizontal & & & 2700 \\
\hline 14 & Krupp & 1 & externo & transversal & Simples & 1 & Lingüeta & Horizontal & & & 2700 \\
\hline 15 & Fitarelli & 1 & externo & transversal & Simples & 1 & Lingüeta & Horizontal & & & 2340 \\
\hline
\end{tabular}


Tabela 2. Média das vazões de sementes de milho, obtidas para três regulagens (mínima, média e máxima) de cada uma das máquinas ensaiadas

\begin{tabular}{|c|c|c|c|c|}
\hline \multirow{3}{*}{ Semeadora } & \multicolumn{4}{|c|}{ Regulagem } \\
\hline & Mínima & Média & Máxima & Variação \\
\hline & \multicolumn{4}{|c|}{ Número de Sementes por ciclo } \\
\hline 1 & 0,50 & 1,68 & 3,10 & 2,60 \\
\hline 2 & 0 & 2,42 & 4,94 & 4,94 \\
\hline 3 & 0 & 2.24 & 3,90 & 3,90 \\
\hline 4 & 0 & 4,50 & 7,65 & 7,65 \\
\hline 5 & 0 & 0,08 & 3,32 & 3,32 \\
\hline 6 & 0 & 1,00 & 1,28 & 1,28 \\
\hline 7 & 0 & 2,00 & 4,98 & 4,98 \\
\hline 8 & 0 & 0,21 & 2,89 & 2,89 \\
\hline 9 & 0 & 2,39 & 10,65 & 10,65 \\
\hline 10 & 0,77 & 1,45 & 3,25 & 2,48 \\
\hline 11 & 0 & 4,84 & 7,27 & 7,27 \\
\hline 12 & 0 & 4,79 & 9,22 & 9,22 \\
\hline 13 & 0 & 0,15 & 0,58 & 0,58 \\
\hline 14 & 0 & 3,75 & 9,67 & 9,67 \\
\hline 15 & 0 & 1,80 & 4,57 & 4,57 \\
\hline
\end{tabular}

10. Não foi possível correlacionar o fluxo de sementes com o tipo de mecanismo dosador, uma vez que o comportamento do fluxo foi bastante diferente em semeadoras com o mesmo tipo de mecanismo.

Durante o ensaio de dosagens individuais foram obtidos valores de 0 a 8 sementes por ciclo, mesmo estando as semeadoras reguladas para operarem com a dosagem de 2 sementes por ciclo. Expressou-se a qualidade da operação das máquinas através do percentual do número de vezes em que as máquinas depositaram o número designado de sementes no total de ciclos, cujo parâmetro é aqui denominado índice de acertos. Na Tabela 3 são apresentados os resultados do ensaio de regularidade de dosagens individuais e, na Figura 3, são apresentadas as médias de índice de acertos, obtidas para as máquinas ensaiadas. Somente as máquinas 1, 3, 4 e 10 obtiveram média de acerto superior a 50\%, enquanto algumas das máquinas ensaiadas, como as semeadoras 2, 6, 11 e 13, apresentaram coeficiente de variação do índice de acertos muito elevado, o que caracteriza a baixa acurácia do seu mecanismo dosador.

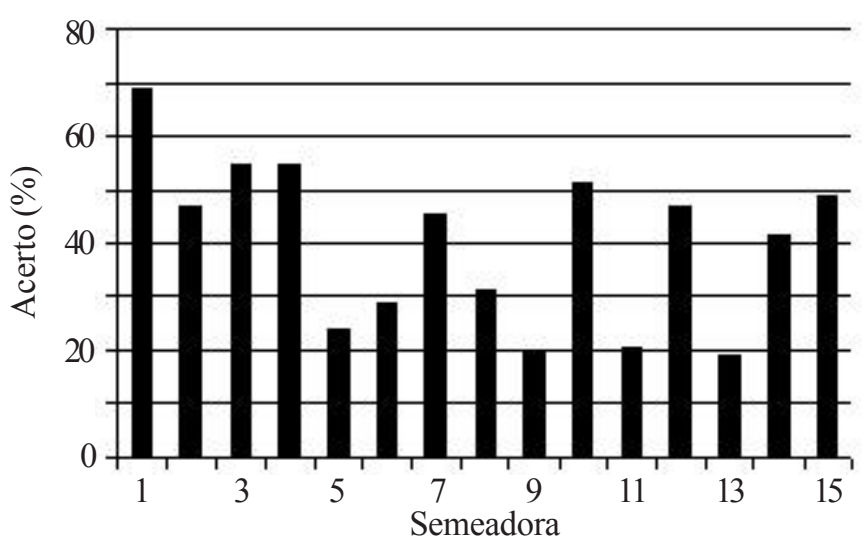

Figura 3. Qualidade de desempenho dos mecanismos dosadores das semeadoras ensaiadas, expresso pelo índice de acertos (duas sementes por cova)

Várias semeadoras obtiveram valores bastante próximos de 2 sementes por ciclo, como média; no entanto, resultaram em desvio-padrão elevado, que é uma medida da qualidade da operação ou como os dados estão dispersos em torno da média. A semeadora 9 , por exemplo, atingiu o valor médio mais próximo de 2 sementes por ciclo, porém com elevado desvio-padrão, baixo índice de acerto e coeficiente de variação de $10 \%$ entre as repetições; já as semeadoras 10 e 15 obtiveram baixos valores de desvio-padrão e de variação, conjugados com alto índice de acerto; no entanto, a média de sementes por ciclo ficou aquém do esperado. Este comportamento pode ser explicado parcialmente por deficiências de regulagem e, nesses casos, os mecanismos dosadores deveriam permitir abertura maior, para que as semeadoras atingissem a população desejada. Os valores de baixo índice de acerto, alto coeficiente de variação entre repetições e alto desvio-padrão obtidos por algumas semeadoras, independente da média de semente por ciclo, indicam problemas estruturais ou falhas nos mecanismos dosadores, que permitem a ocorrência de grandes variações no número de sementes depositado por ciclo. A qualidade construtiva e acabamentos das máquinas, em particular dos mecanismos dosadores, são essenciais para a obtenção de regularidade na deposição de sementes. As semeadoras 1 e 4 foram as que produziram melhores resultados, com média mais

Tabela 3. Resultados do ensaio de caracterização da regularidade de dosagem individual de sementes para todas as máquinas ensaiadas

\begin{tabular}{|c|c|c|c|c|c|}
\hline \multirow{2}{*}{ Semeadora } & $\begin{array}{l}\text { C.V. entre } \\
\text { Repetições }\end{array}$ & $\begin{array}{c}\text { Índice de } \\
\text { Acerto }\end{array}$ & \multirow{2}{*}{$\begin{array}{c}\text { Média } \\
\text { (sementes por } \\
\text { ciclo) }\end{array}$} & \multirow{2}{*}{$\begin{array}{l}\text { Desvio-Padrão } \\
\text { da Média }\end{array}$} & \multirow{2}{*}{$\begin{array}{c}\text { População Final } \\
\text { Estimada } \\
\text { (plantas ha }^{-1} \text { ) }\end{array}$} \\
\hline & \multicolumn{2}{|c|}{$(\%)$} & & & \\
\hline 1 & 8,9 & 68,7 & 2,17 & 0,817 & 43467 \\
\hline 2 & 42,1 & 46,7 & 2,17 & 0,808 & 43467 \\
\hline 3 & 9,2 & 54,7 & 1,94 & 0,998 & 38800 \\
\hline 4 & 15,2 & 54,7 & 2,06 & 0,767 & 41200 \\
\hline 5 & 16,7 & 24,0 & 1,48 & 1,216 & 29600 \\
\hline 6 & 40,9 & 28,7 & 1,53 & 1,313 & 30667 \\
\hline 7 & 15,5 & 45,3 & 1,83 & 0,996 & 36667 \\
\hline 8 & 9,8 & 31,3 & 2,13 & 1,119 & 42533 \\
\hline 9 & 10,0 & 20,0 & 2,02 & 1,764 & 40400 \\
\hline 10 & 12,5 & 51,3 & 1,87 & 0,881 & 37467 \\
\hline 11 & 36,6 & 20,7 & 1,33 & 1,198 & 26667 \\
\hline 12 & 13,1 & 46,7 & 1,91 & 0,853 & 38267 \\
\hline 13 & 72,7 & 19,3 & 1,91 & 1,420 & 38267 \\
\hline 14 & 7,4 & 41,3 & 1,97 & 1,059 & 39467 \\
\hline 15 & 4,7 & 48,7 & 1,43 & 0,702 & 28533 \\
\hline
\end{tabular}


próxima de 2 sementes por ciclo e respectivo baixo desvio-padrão, também com baixo coeficiente de variação entre repetições. As semeadoras 1, 2, 3, 4, 7, 10, 12 e 14, apresentaram distribuição que se aproxima de uma curva normal quanto às freqüências médias do número de sementes depositadas, correlacionada ao baixo desvio-padrão. As semeadoras 5, 6, 9, 11 e 13 tiveram comportamento disperso, apresentando freqüências semelhantes para várias classes de freqüência. Exemplos de comportamento distinto quanto à regularidade de distribuição transversal, são apresentados na Figura 4. Com pequenas melhorias nos mecanismos dosadores, é possível que sejam obtidas melhores regularidades de distribuição dessas máquinas.

\section{A. Semeadora 1}

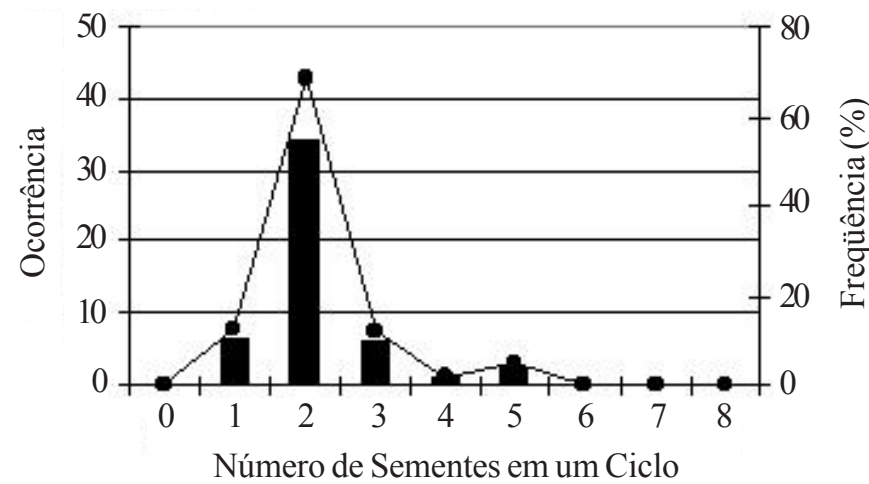

B. Semeadora 5

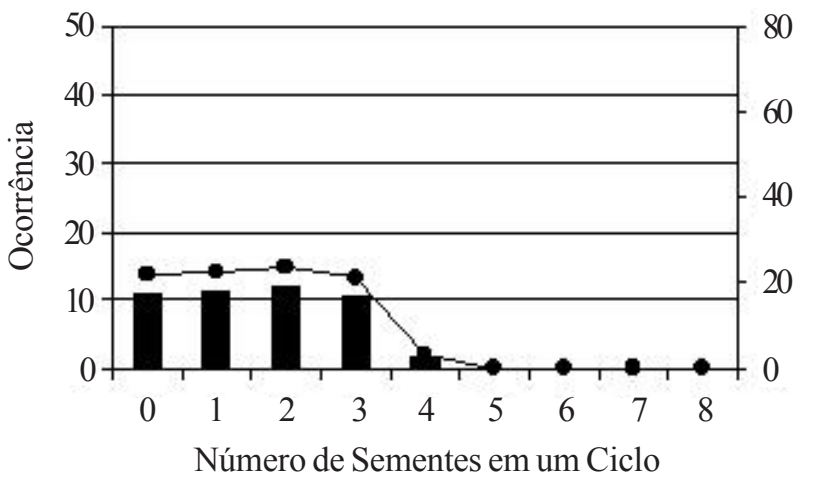

Figura 4. Exemplos de comportamento de distribuição do número de sementes por ciclo, obtidos no ensaio de dosagens individuais onde eram desejadas duas sementes por ciclo: A) distribuição normal; B) distribuição dispersa

\section{CONCLUSÕES}

1. A metodologia empregada para se avaliar o desempenho das máquinas mostrou-se satisfatória, permitindo a caracterização do desempenho das semeadoras.

2. O melhor índice de acertos (duas sementes por ciclo) foi de $68,7 \%$, e o pior de $19,3 \%$.

3. Parte significativa dos resultados deveu-se aos aspectos de qualidade construtiva das máquinas e não aos diferentes princípios dos mecanismos dosadores utilizados.

4. A variação no comportamento das máquinas é elevada, sendo poucas as que apresentaram comportamento satisfatório.

\section{LITERATURA CITADA}

Casão Júnior, R.; Siqueira, R.; Yamaoka, R.S.; Araújo, A.G. de E.; Figueiredo, P.R.A. de. Adaptação e desenvolvimento do arado de aiveca a tração animal "Tamanduá-IAPAR". Londrina, 1988. 29p. IAPAR, Circular, 54

Casão Júnior, R.; Yamaoka, R.S. Desenvolvimento de semeadora-adubadora direta a tração animal. In: Congresso Brasileiro de Engenharia Agrícola, 19, Piracicaba. Anais... Piracicaba: SBEA, v.2, 1990. p.766-777.

Casão Júnior, R.; Yamaoka, R.S.; Figueiredo, P.R.A. de.; Siqueira, R., Araújo, A.G. de. Estudo e caracterização de semeadoras adubadoras a tração animal no Paraná. In: Congresso Brasileiro de Engenharia Agrícola, 15, 1986, Botucatu. Anais... Botucatu: SBEA, 1986. p.305.

Lal, H.E.; Nunes, P.F. Multicultor CPATSA: fabricação e uso. Petrolina: EMBRAPA-CPATSA, 1981. 96p. Circular Técnica, 6

Mialhe, L.G.; Balastreire, L.A.; Milan, M.; Nakamura, R.T.; Ripoli, T.C.C.; Neves, E.M.; Noronha, J.F. de; Molina Filho, J. Projeto mini-trator agrícola - Relatório final do projeto. Piracicaba: FEALQ/ESALQ-USP. 1985. 135p.

Molin, J.P.; Ogliari, P.J. Caracterização do desempenho de alguns modelos de arados de tração animal no oeste de Santa Catarina. In: Congresso Brasileiro de Engenharia Agrícola, 19, Piracicaba. Anais... Piracicaba: SBEA, v.2, 1990, p.695-711.

Monegat, C. Plantio direto em Santa Catarina. Revista Plantio Direto, Passo Fundo, n.35, maio-junho, p.15-16, 1996. 